\title{
Synchronous occurrence of two primary gynaecological tumors: A case report
}

\author{
Puja Kumari ${ }^{1, *}$, Manika Agarwal ${ }^{2}$, A. Santa Singh ${ }^{3}$ \\ ${ }^{\mathbf{1}}$ Resident Doctor, ${ }^{\mathbf{2}}$ Assistant Professor, ${ }^{3}$ Professor, Dept. of Obstetrics and Gynecology, North Eastern Indira Gandhi Regional \\ Institute of Health and Medical Sciences, Shillong, Meghalaya, India \\ *Corresponding Author: \\ Email: drrajeevsingh1982@gmail.com
}

Received: $10^{\text {th }}$ April, 2018

Accepted: $18^{\text {st }}$ April, 2018

\begin{abstract}
Synchronous occurrence of two primary tumors is rare. Endometrial and ovarian cancers are the most frequently simultaneously occurring primary tumors. Here we are presenting, similar rare presentation of 40 years old lady who has been referred to us with complaint of abnormal uterine bleeding and lump abdomen since one year. Patient underwent total abdominal hysterectomy and bilateral salpingoopherectomy with surgical staging. Histopathological examination showed moderately differentiated endometroid ovarian carcinoma and endometroid adenocarcinoma of uterus with metastasis to cervix.
\end{abstract}

Keywords: Synchronous, Primary tumors, Endometrial cancer, Ovarian cancer.

\section{Introduction}

Simultaneous occurrence of two primary gynaecological tumors is a rare phenomenon. But synchronous endometrioid carcinoma of uterus and the ovary are found with reported incidence of $1.4-3.8 \%{ }^{1}$ Such tumors may be two different primaries or a single primary with metastasis. These tumors present real diagnostic and therapeutic challenge.

\section{Case Report}

A 40 year old lady had presented to Obstetrics and Gynaecology OPD with chief compliants of abnormal uterine bleeding and large abdominal mass of one year duration. She was para 4 with 4 living issues. She approached a doctor earlier for her complaint, where pap smear and endometrial biopsy was taken which showed inflammatory smear and endometrial adenomatous hyperplasia with atypia respectively. USG showed increased endometrial thickness $-1.9 \mathrm{~cm}$ with normal ovary. She was managed conservatively and referred to our hospital one year later. At the time of Admission patient was stable. On general examination pallor was present. On abdominal examination, mass of 18 weeks were palpable. Cervix and vagina was healthy on per spectrum examination. On per vaginam examination, uterus was bulky and irregular firm mass was felt on adnexa. USG showed right sided Ovarian mass with internal cysts. Ca-125 was $243.24 \mathrm{iu} / \mathrm{ml}$. Patient underwent total abdominal hysterectomy and bilateral salpingoopherectomy with staging. Per operatively right ovary was enlarged, $(17-18 \mathrm{~cm})$ irregular, solid and bilobular with a uterine size of 12 weeks (Fig. 1) and was removed. Post operative period was uneventful. Patient was referred to oncologist and received post- op radiotherapy. On follow up after 1 year patient was doing well.

On histopathologal examination sections from endometrial growth, features consistent with moderately differentiated endometrioid adenocarcinoma with focal areas of poor differentiation and myoinvasion involving the inner third of myometrium, was seen. There was downward extension of growth up to the endocervical canal.

Multiple sections from right ovarian mass shows feature consistent with moderately differentiated endomtrioid carcinoma of ovary with focal areas of poorly differentiated endometrioid carcinoma and focal area of sqamous differentiation, haemorrhages and necrosis.

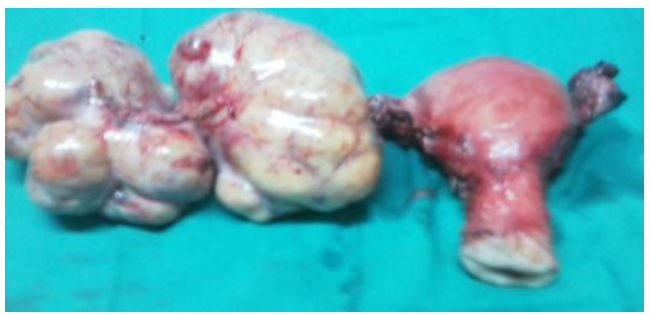

Fig. 1: Bilobular right ovarian tumor with enlarged uterus

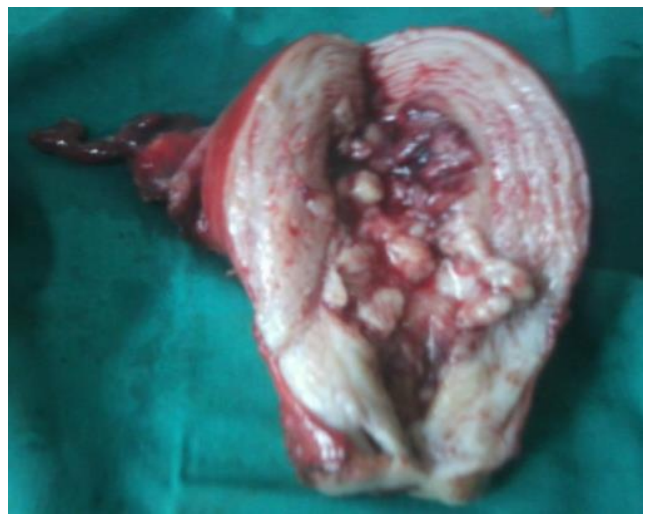

Fig. 2: Cut section of uterus showing exophytic papillary growth 


\section{Discussion}

Synchronous primary tumors of endometrium and ovary are found in 5\% women with endometial cancers and $10 \%$ of women with ovarian cancer. ${ }^{2}$ These are rare and diagnosed incidentally on specimen removed surgically.

In our case, history of precancerous adenomatous hyperplasia with atypia is strongly suggestive of primary endometrial tumor. Several gross and histological features helped to differentiate primary tumors from meastatic. Absence of deep myometrial invasion, lymphvascular invasion, oviduct affection and absence of surface implants and bilterality is strongly suggestive of two different primaries.

Ree YS et al reported a case of 46 years old lady who presented with abnormal vaginal bleeding, was found to have stage 1c clear cell carcinoma of left ovary, stage 1a borderline mucinous cyst adenoma of right ovary and stage $1 \mathrm{~b}$ endometriod uterine tumor. ${ }^{3}$ Patients with synchronous cervical and endometrial cancers have also been reported in literature. A case of endometrial adenocarcinoma and cervical large B cell lymphoma in 64 years old lady had been reported. ${ }^{4}$

Immunohistochemical studies, flow cytometry, and assessment of molecular DNA patterns to detect loss of heterozygosity may be helpful in distinguishing between metastatic and independent tumors, independent tumors, but differential diagnosis can be determined by conventional clinical and pathological criteria. Using International federation of Gynaecology and Obstetrics guidelines a patient diagnosed with dual primaries confined to the ovary and uterus represent two stage I cancers. These patients have good prognosis and depending on the substage may not require radio or chemotherapy. By contrast primary endometrioid ovarian carcinoma and endometrial metastasis would be stage IIA cancer and primary endometrial carcinoma with ovarian metastasis would be stage III A and require aggressive treatment. ${ }^{5}$

To conclude it is necessary to identify synchronous primaries and primary with metastatic tumours correctly as staging, prognosis and further management depend upon it.

\section{References}

1. Simultaneous tumors of endometrium and ovary. Novac gynaecology fifteenth edition chapter-35-p-1263.

2. Zaino R, Whitney C, Brady M, Degeest K, Burger R, Buller R. Simultaneously detected endometrial and ovarian carcinomas - a prospective clinicopathologic Study of 74 cases: a Gynecologic Oncology Group Study. Gynecol Oncol. 2001;83:355-362.

3. Ree YS, Sho SH, Kim SR, Cho SH, Kim KT, Park MH. Synchronous primary endometrial and ovarian cancer with three different histologic patterns: A case report. Int J Gynecologic cancer. 2003;13(5):678-682.

4. Kostopoulos IS, Barbanis SB, Kalousti VD, Papadimitriou CS. Patho Res Pract. 2000;196(8):573575.

5. Momcilo D, Slobodanka M, Gordana D, Boziddar J. Endometroid tumor of the ovary and uterus, metastasis or not - case report. Acta Medica Medianae. 2007;47(4):1519.

How to cite this article: Kumari P, Agarwal M, Singh AS. Synchronous occurrence of two primary gynaecological tumors: A case report. Ind J Obstet Gynecol Res. 2018;5(3):436-437. 